\title{
As dimensões dos direitos das águas ${ }^{\star}$ The dimensions of the water rights
}

\author{
Ana Alice De Carli*
}

\section{RESUMO:}

Trata-se o presente texto de uma reflexão acerca da importância de se analisar o líquido vital, a água, a partir de três perspectivas jurídicas, quais sejam: a água como direito fundamental dos seres vivos; a água como titular de direitos; e a água como bem jurídico que necessita de um conjunto de regras e princípios para disciplinar a conduta antrópica, a fim de preservá-la e protegê-la.

\section{PALAVRAS-CHAVE:}

Direito à água - direito de águas - direito das águas

* Artigo recebido em 30 de julho de 2015 e aprovado em 11 de junho de 2016. DOI: http://dx.doi. org/10.12660/rda.v276.2017.72993.

** Universidade Federal Fluminense, Niterói, Rio de Janeiro, Brasil. E-mail: anacarli@id.uff.br. Doutora e mestre em direito público e evolução social. Especialista em direito público. Professora adjunta do curso de direito e do mestrado em tecnologia ambiental da Universidade Federal Fluminense (UFF). Pesquisadora-líder do Grupo de Estudos em Meio Ambiente e Direito (Gemadi/UFF). Pesquisadora colaboradora do "Proyecto de Investigación Sustentabilidad y Desarrollo: perspectivas para la construción de um estado de derecho ambiental em Brasil y Costa Rica", coordenado pelo prof. dr. Carlos E. Peralta, da Universidad de Costa Rica. Membro da Comissão de Meio Ambiente da OAB/RJ. Parecerista de periódicos. 
SUMMARY:

It is the present text a simple reflection about the importance of analysing the vital liquid, water, from three legal perspectives, namely: water as a fundamental right of living beings; water as a holder of rights; and the legal water as well that requires a set of rules and principles to regulate the anthropic conduct in order to preserve it and protect it.

\section{KEYWORDS:}

Fundamental right to water - water rights - water law

\section{Introdução}

A teoria dos direitos fundamentais (ou qualquer outra nomenclatura utilizada para se referir a interesses subjetivos públicos dos homens) tem sido desenvolvida a partir de uma visão eminentemente antropocêntrica, a qual coloca o ser humano no centro das preocupações.

A rigor, já na Antiguidade era possível extrair aspectos dos direitos fundamentais voltados à proteção dos indivíduos. A Bíblia Sagrada, no livro de Gênesis, por exemplo, faz referência ao homem como a imagem de Deus. Ainda, no referido livro vislumbra-se o direito à vida digna, quando Deus se refere aos recursos naturais como meio de subsistência do homem, ${ }^{1}$ o que não sugere a equivocada interpretação de que a natureza estaria à disposição dos seres humanos para dela usufruírem sem o devido cuidado e respeito.

Depois, no período medieval, os direitos naturais (fundamentais) ganharam vulto, especialmente pela doutrina de Santo Tomás de Aquino, que defendia a igualdade como um valor intrínseco à vida do homem em relação. ${ }^{2}$ É, de fato, inegável a contribuição do cristianismo para o desenvolvimento do conceito de igualdade material ou isonomia, de fraternidade ou solidariedade e de dignidade humana. ${ }^{3}$

1 BÍBLIA SAGRADA. Livro de gênesis. Tradução de João Ferreira de Almeida. Brasília: Sociedade Bíblica do Brasil. 1990. p. 2. Conforme Gênesis, cap. 1, versículo 29, in verbis: "E disse Deus: Eis que vos tenho dado toda a erva que dá semente, que está sobre a terra; e toda a árvore, em que há fruto de árvore que dá semente, ser-vos-á para mantimento".

2 SARLET, Ingo Wolfgang. A eficácia dos direitos fundamentais. 7. ed. rev., atual. e ampl. Porto Alegre: Livraria do Advogado, 2007a. p. 45-46.

3 OLIVEIRA, Almir de. Curso de direitos humanos. Rio de Janeiro: Forense, 2000. p. 107-108. Nesta época, a dignidade humana ganhou destaque em detrimento da regra segundo a qual o direito 
Da fase medieval para a Idade Moderna muitas transformações socioeconômicas e culturais ocorreram, tendo como fatores determinantes o acentuado desenvolvimento do comércio marítimo, a ascensão da burguesia e a reforma protestante.

Diante desse cenário, novos pensamentos começaram a ecoar nos campos científico e filosófico, os quais alçaram o homem ao centro das discussões. Nesse sentido, pontua Almir de Oliveira: ${ }^{4}$

O humanismo renascentista procurou compreendê-lo [o homem] como um ser dotado de liberdade e dignidade próprias, finito e histórico, integrado na natureza e na sociedade, apto a conhecer o universo mediante a observação e a pesquisa, bem como a transformar o mundo. O racionalismo, a começar de Descartes, acentuou a valorização do indivíduo, afirmando a sua independência em relação à autoridade científica e à filosofia, pela ênfase que deu à investigação e à meditação.

No final do século XVIII, com a eclosão da Revolução Francesa, escreveuse nova página na história dos direitos dos homens, especialmente por influência dos movimentos iluminista e renascentista, sendo digna de registro a insatisfação do povo francês com o sistema feudal. Os séculos XVIII e XIX foram marcados pelo individualismo, corolário do pensamento liberal, defendido por vários pensadores, entre os quais se destacam John Locke e Immanuel Kant, para os quais os direitos naturais assumiam feições diversas. Enquanto, para John Locke, ${ }^{5}$ a vida, a liberdade e a propriedade compreendiam espécies do gênero direitos naturais, para Immanuel Kant, ${ }^{6}$ o direito de liberdade era um direito natural por excelência, abarcando os demais direitos.

era "uma dádiva do rei ou do Estado". Os princípios cristãos de igualdade, fraternidade e solidariedade se entrelaçavam, formando um imperativo normativo de respeito mútuo entre os homens.

4 Ibid., p. 111-112. A referida travessia da Idade Média para a Idade Moderna pode ser demarcada por dois marcos: no período medieval vigia o pensamento teocêntrico, ou seja, as normas vinham do "Divino", já a fase moderna consagra a visão antropocêntrica, isto é, o indivíduo exsurge "como a firmação de suas liberdades e de seus direitos", afirma o autor.

5 LOCKE, John. Segundo tratado sobre o governo civil e outros escritos. Tradução de Magda Lopes e Marisa Lobo da Costa. 3. ed. Petrópolis: Vozes, 2001. p. 69.

6 KANT, Immanuel. A metafísica dos costumes. Tradução, textos adicionais e notas de Edson Bini. São Paulo: Edipro, 2003. p. 40. Ensina o filósofo: “a liberdade (a independência de ser constrangido pela escolha alheia), na medida em que pode coexistir com a liberdade de todos os outros de acordo com uma lei universal, é o único direito original pertencente a todos os homens em virtude da humanidade destes". 
O entusiasmo libertário do individualismo, entretanto, começou a perder força a partir do momento em que os homens começaram a se dar conta do crescimento acelerado das desigualdades materiais, as quais eram evidentes, especialmente após a Primeira Guerra Mundial. Tal situação agravou-se com a Revolução Industrial, haja vista os diversos conflitos entre trabalhadores e interesses capitalistas.?

No século XVIII, sublinha-se três paradigmáticos documentos sobre direitos humanos: 1. a Declaração da Independência dos Estados Unidos da América, de 1776, que afirma os ideais de democracia, calcados na vontade do povo, bem como a natureza inalienável dos direitos humanos; 2. a Declaração de Direitos de Virgínia, de 1776, a qual proclama o direito à liberdade e à existência de direitos natos; e 3. a Declaração dos Direitos do Homem e do Cidadão francesa, de 1789, que consagra as características da universalidade e da fundamentalidade aos valores de liberdade, igualdade, propriedade, segurança e resistência à opressão etc. ${ }^{8}$

O século XIX, por sua vez, destacou-se pela evolução dos direitos humanos sociais, econômicos e culturais, em especial, a partir da Constituição mexicana, de 1917, e da Constituição alemã de Weimar, de 1919, visto que ambas trouxeram um significativo rol desses direitos, o que foi seguido por diversos países.

Nesse passo, cabe, ainda, realçar a promoção universal ${ }^{9}$ dos direitos humanos, em documentos internacionais, como: a Declaração Universal de Direitos do Homem da ONU, de 1948; a Carta Internacional Americana de Garantias Sociais, de 1948 (OEA); a Convenção Europeia de Direitos do Homem, de 1950; o Pacto Internacional de Direitos Econômicos, Sociais e Culturais e o Pacto Internacional de Direitos Civis e Políticos, da ONU, ambos de $1966 .{ }^{10}$

Outras correntes doutrinárias também defendem que há mais titulares de direitos fundamentais, além dos homens; como os direitos dos Estados, dos animais e da natureza ${ }^{11}-$ aqui se insere os direitos das águas. A natureza

Almir de Oliveira, Curso de direitos humanos, op. cit., p. 119.

Ibid., p. 117-118.

Cumpre de pronto destacar que, embora não se objetive, neste trabalho, abordar a discussão acerca da ideia de universalização dos direitos humanos fundamentais, cabe menção à obra de RUBIO, David Sánches. Repensar derechos humanos: de la anesthesia a la sinestesia. Sevilha: Mad, S.L., 2007. p. 84-100. Nela o autor espanhol aborda o tema a partir de três perspectivas: o poder e o aparente duplo interesse; a globalização e a universalidade; e a inversão ideológica e negação de direitos.

10 Almir de Oliveira, Curso de direitos humanos, op. cit., p. 45-50.

11 Vide DE CARLI, Ana Alice. A água e seus instrumentos de efetividade: educação ambiental, normatização, tecnologia e tributação. São Paulo: Millennium, 2013. 
também pode ser sujeito de direitos, apregoa Leonardo Boff, ${ }^{12}$ na esteira de James Lovelock, Lynn Margulis, entre outros, argumenta que a Terra pode ser "sujeito de dignidade e de direitos". O pensador brasileiro refere-se à terra, não como aquele bem econômico, passível de apropriação, mas como um ser vivo, a "Mãe Terra", como designada pela Assembleia Geral da ONU, em 22 de abril de 2009, ou Pacha Mama, como a natureza é carinhosamente chamada pelos equatorianos em sua Carta Magna de 2008.

Na perspectiva da classificação dos direitos fundamentais, é possível posicionar os direitos da natureza a partir de três dimensões: 1 . como direitos de terceira dimensão ou geração de direitos fundamentais; 2. como direitos transindividuais, ${ }^{13}$ ou, ainda, 3. como uma nova dimensão de direitos.

No que se refere ao surgimento dos direitos de terceira dimensão (também denominados de direitos da fraternidade, da solidariedade), vale destacar que eles ganharam vulto no cenário pós-Segunda Guerra Mundial, em meados do século XX, período no qual o mundo, em especial a Europa, tentava recompor-se dos danos da guerra. No rol dessa categoria de direitos estão, por exemplo: os direitos ao meio ambiente saudável e equilibrado, à vida digna, à saúde, à paz, ao desenvolvimento, à comunicação, ao acesso à água potável e ao acesso ao saneamento básico de esgoto e coleta de lixo.

Os direitos transindividuais ou metaindividuais, como os termos sinalizam, ultrapassam a esfera meramente individual, afastando-se da clássica dicotomia entre público e privado, vinculando-se ao interesse público, conceituado por Celso Antonio Bandeira de $\mathrm{Mello}^{14}$ como a "dimensão pública dos interesses individuais; plexo dos interesses dos indivíduos enquanto partícipes da Sociedade (entificada juridicamente no Estado)".

Tem-se assim que os direitos transindividuais ou metaindividuais consubstanciam os direitos coletivos em sentido amplo, amalgamando as espécies, que são: os direitos coletivos em sentido estrito, os direitos difusos, os direitos individuais homogêneos, os direitos individuais indisponíveis e os direitos da natureza.

Por fim, conforme apontado, os direitos da natureza e, por conseguinte, dos demais seres vivos que a compõem podem ser alçados à categoria de uma

12 BOFF, Leonardo. Cuidar da terra, proteger a vida: como evitar o fim do mundo. Rio de Janeiro: Record, 2010. p. 40.

13 VIANA, Thiago Henrique Fedri. Manual dos direitos difusos e coletivos. Campinas, SP: Millennium, 2010. p. 4.

14 MELLO, Celso Antonio Bandeira de. Curso de direito administrativo. 17. ed. São Paulo: Malheiros, 2004. p. 56. 
dimensão própria, autônoma em relação às demais dimensões já sugeridas pela doutrina, visto que os bens naturais são pressupostos necessários à existência dos demais direitos. Não é possível vislumbrar vida sem água, por exemplo, tampouco desenvolvimento econômico.

Nesse contexto, buscar-se-á demonstrar que a água, considerada a partir de suas múltiplas funções, pode ser titular de direitos e possuir dignidade, enquanto ser vivo da natureza. Ainda, a água como bem ambiental, ou seja, como recurso natural, precisa da tutela do Estado, seja por meio de normatização ou de regulação, com o objetivo de disciplinar a conduta antrópica em relação aos seus usos. E, por derradeiro, a água, como bem essencial à vida, deve ser analisada a partir da perspectiva dos direitos fundamentais.

Nessa linha de pensamento defende-se a existência de três dimensões de direitos para a água, conforme será demonstrado a seguir.

\section{Direito à água}

O direito à água, dentro do estudo do direito, consubstancia um direito fundamental dos seres humanos, dos animais e da própria natureza (a qual, como se verá adiante, tem sido alçada, por alguns estudiosos, ao patamar de sujeito de direitos).

Por que o direito precisa disciplinar e tutelar esse elemento da natureza, e, ainda, qualificá-lo como direito fundamental? A resposta não requer muita reflexão, porque sem água - repise-se - não há vida, tampouco desenvolvimento econômico. ${ }^{15}$

Paulo Affonso Leme Machado ${ }^{16}$ ressalta que "o direito de usar a água [...] para consumo pessoal faz parte inseparável do direito à vida", importando na concretização do "princípio da satisfação das necessidades vitais básicas", consagrado na Convenção sobre o direito relativo à utilização dos cursos de água internacionais para fins diversos dos de navegação, da ONU, de 1997. Para a indiana Vandana Shiva, ${ }^{17}$ os direitos à água são natos, não se originando da

15 DE CARLI, Ana Alice. Água é vida: eu cuido, eu poupo - por um futuro sem crise. Rio de Janeiro: Editora FGV, 2015. (FGV de Bolso, Direito e Sociedade, 39).

16 MACHADO, Paulo Affonso Leme. Direito dos cursos de água internacionais. São Paulo: Malheiros, 2009. p. 171.

17 SHIVA, Vandana. Guerras por água: privatização, poluição e lucro. Tradução de Georges Kormikiaris. São Paulo: Radical Livros, 2006. p. 32-37. 
normativa estatal; "eles surgem de um dado contexto ecológico da existência humana", pontifica a ecologista, o que justifica a necessidade de sua proteção, impondo a construção de um arcabouço normativo e regulatório.

São elementos intrínsecos da água a essencialidade e a fundamentalidade, os quais a transformam, por excelência, em um direito natural, a despeito de o direito positivado contemplá-lo ou não. Evidencia-se, entretanto, que o reconhecimento do direito fundamental ao acesso à água potável pelo Estado reforça sua importância, tornando sua observância norma coercitiva, além de servir, em tese, de instrumento de conscientização de toda a sociedade.

Nesse sentido, considerando o aspecto vital da água, Elaine Tavares ${ }^{18}$ sustenta que o direito à água potável corporifica um direito natural, e chama atenção para a importância de se garantir sua efetividade, para fins de realização de outros direitos e garantias fundamentais do homem, porquanto, sem o acesso equitativo à água tratada, não se configura o respeito à dignidade da pessoa humana.

Não há dúvida de que a realização material do direito fundamental ao acesso à água com qualidade depende não apenas do aspecto quantitativo desta riqueza finita, mas de políticas de saneamento básico, pois a inexistência de ações voltadas para o tratamento do esgoto e do lixo reflete na saúde das águas, cujos danos muitas vezes são irreversíveis.

Ainda, no tocante aos mencionados elementos, essencialidade e fundamentalidade, Ingo Wolfgang Sarlet ${ }^{19}$ assevera que a fundamentalidade, da perspectiva material, "decorre da circunstância de serem os direitos fundamentais elemento constitutivo da Constituição material, contendo decisões fundamentais sobre a estrutura básica do Estado e da sociedade" ${ }^{20}$ Nessa trilha, visualizase, por força do art. $5^{\circ}, 2^{2}$, da CR/88, duas vertentes de direitos fundamentais: a uma, aqueles de natureza dúplice, formal e material (estabelecidos na Constituição formal); e a duas, os direitos materialmente fundamentais (sem previsão expressa na Carta Constitucional).

18 TAVARES, Elaine. Água potável - direito fundamental do ser humano. Disponível em <www. recantodasletras.com.br/discursos/791994>. Acesso em: 25 jul. 2011.

19 Ingo Wolfgang Sarlet, A eficácia dos direitos fundamentais, op. cit., p. 88-89.

20 Ibid., p. 88-98. Ensina o autor que a fundamentalidade pode variar de Estado para Estado, isto é, o que é fundamental para uma organização política pode não o ser para outra. Defende, no entanto, a existência de valores universais, como a vida, a liberdade, a igualdade e a dignidade humana; os quais ainda podem ser axiologicamente ponderados de forma distinta, dependendo do espaço cultural e temporal. 
Já o aspecto da essencialidade ${ }^{21}$ vincula-se à natureza do interesse protegido, servindo de parâmetro de mensuração da fundamentalidade, a partir da análise de determinada situação fática. Posto de outra forma: quando estiverem em colisão dois direitos/interesses materialmente fundamentais, dever-se-ão considerar as circunstâncias do fato da vida, o grau de interferência no núcleo de cada interesse em jogo.

Nessa trilha, é inconteste a afirmação de que a água é um direito fundamental. Corroborando com este entendimento, João Marcos Adede y Castro ${ }^{22}$ anuncia:

As águas, como um dos recursos naturais colocados à disposição do homem pela natureza, são parte do conjunto de direitos fundamentais, em vista de disposições feitas pela Constituição Federal de 1988, no sentido de garantir a todos um ambiente sadio, para as presentes e futuras gerações.

Ainda, cumpre realçar que o direito fundamental à água com qualidade está intrinsecamente atrelado aos direitos à vida, à saúde, ao desenvolvimento econômico, bem como à dignidade da pessoa humana (princípio elevado pela Constituição da República do Brasil de 1988, art. 1º, inciso III, à categoria de norma norteadora de todo sistema normativo).

Segundo a Organização das Nações Unidas para a Alimentação e Agricultura (FAO), o consumo de água diária pelo ser humano deve ser de, no mínimo, 40 litros. ${ }^{23}$ Outra agência das Nações Unidas, a Organização Mundial de Saúde (OMS), analisa diversos patamares em termos quantitativos diários de água e seus efeitos sobre a saúde das pessoas. A tabela seguinte é bem esclarecedora. ${ }^{24}$

21 Cf. Dicionário eletrônico Houaiss da língua portuguesa, o vocábulo essencial tem sentido multívoco, significando: 1. que é inerente a algo ou alguém; 2. que constitui o mais básico ou o mais importante em algo; 3. que é necessário, indispensável; 4. a coisa principal; 5 . da natureza da essência; etc.

22 ADEDE Y CASTRO, João Marcos. Água: um direito humano fundamental. Porto Alegre: Nuria Fabris, 2008. p. 12-13.

23 Conforme mencionado alhures, no Relatório de Desenvolvimento Humano de 2006, a Organização das Nações Unidas (ONU) recomenda aos Estados que desenvolvam políticas que garantam a todos o acesso à água limpa, por preço razoável e permitam o acesso gratuito de, pelo menos, 20 litros de água por dia à população hipossuficiente economicamente.

24 Disponível em: <www.who.int/water>. Acesso em: 19 jun. 2014. 
Table S1

Summary of requirement for water service level to promote health

\begin{tabular}{|l|l|l|c|}
\hline \multicolumn{1}{|c|}{ Service level } & \multicolumn{1}{|c|}{ Access measure } & \multicolumn{1}{c|}{ Needs met } & $\begin{array}{c}\text { Level of } \\
\text { health }\end{array}$ \\
\hline $\begin{array}{l}\text { No access (quantity } \\
\text { collected often } \\
\text { below } 5 \mathrm{l} / \mathrm{c} / \mathrm{d} \text { ) }\end{array}$ & $\begin{array}{l}\text { More than 1000m or } \\
30 \text { minutes total } \\
\text { collection time }\end{array}$ & $\begin{array}{l}\text { Consumption - cannot be assured } \\
\text { Hygiene - not possible (unless } \\
\text { practised at source) }\end{array}$ & Very High \\
\hline $\begin{array}{l}\text { Basic access } \\
\text { (average quantity } \\
\text { unlikely to exceed } \\
\text { 20 1/c/d) }\end{array}$ & $\begin{array}{l}\text { Between } 100 \text { and } \\
1000 \text { m or } 5 \text { to } \\
30 \text { minutes total } \\
\text { collection time }\end{array}$ & $\begin{array}{l}\text { Consumption - should be assured } \\
\text { Hygiene - handwashing and basic } \\
\text { food hygiene possible; laundry/ } \\
\text { bathing difficult to assure unless } \\
\text { carried out at source }\end{array}$ & High \\
\hline $\begin{array}{l}\text { Intermediate access } \\
\text { (average quantity } \\
\text { about 50 1/c/d) }\end{array}$ & $\begin{array}{l}\text { Water delivered } \\
\text { through one tap } \\
\text { onplot (or within } \\
100 m \text { or } 5 \text { minutes } \\
\text { total collection time) }\end{array}$ & $\begin{array}{l}\text { Consumption - assured } \\
\text { Hygiene - all basic personal and } \\
\text { food hygiene assured; laundry and } \\
\text { bathing should also be assured }\end{array}$ & Low \\
\hline $\begin{array}{l}\text { Optimal access } \\
\text { (average quantity } \\
\text { 100 1/c/d and } \\
\text { above) }\end{array}$ & $\begin{array}{l}\text { Water supplied } \\
\text { through multiple } \\
\text { taps ontinuously }\end{array}$ & $\begin{array}{l}\text { Consumption - all needs met } \\
\text { Hygiene - all needs should be met }\end{array}$ & Very Low \\
\hline
\end{tabular}

Fonte: <www.who.int/water>. Acesso em: 19 jun. 2014.

De acordo com os dados apresentados na tabela, têm-se os seguintes panoramas: 1) o consumo-dia de água por pessoa inferior a cinco litros pode trazer altos riscos à saúde; 2) o consumo equivalente a 20 litros diários serve, em tese, para o suprimento da higiene básica e para a alimentação, não garantindo, porém, a lavagem de roupa, e acarretando, segundo os dados da tabela, efeitos negativos à saúde; 3) o consumo do líquido vital de aproximadamente 50 litros diários por pessoa garante a higiene pessoal, a alimentação e a lavagem de roupas, implicando baixo índice de problemas de saúde; e, por fim, 4) o consumo diário por indivíduo dentro do patamar de 100 litros, consoante a mencionada tabela, cumpre o mínimo existencial digno, pois seria possível suprir as necessidades básicas de qualquer pessoa, diminuindo os riscos de doença, ou seja, poucos seriam os efeitos negativos sobre a saúde.

Infelizmente, o direito ao acesso à água potável está longe de ser uma realidade para muita gente. Calcula-se que mais de um bilhão de pessoas não tem acesso ao líquido vital e mais de dois bilhões ainda não dispõem de 
serviços de saneamento básico. Na África, por exemplo, centenas de mulheres passam o dia em busca de água. ${ }^{25}$

A propósito, em entrevista concedida ao jornalista Tiago Dantas, do jornal O Globo, do dia 8 de novembro de 2014, o engenheiro especializado em recursos hídricos Leo Heller (assumiu em dezembro de 2014 a relatoria especial da ONU para os direitos à água e ao saneamento básico) afirmou que uma das causas para os problemas de acesso à água com qualidade e quantidade é a falta de planejamento adequado, ressaltando o caso recente de escassez de água no maior estado brasileiro em densidade demográfica e desenvolvimento de atividades econômicas, São Paulo.

De fato, o planejamento é uma ferramenta importante para a gestão dos recursos naturais. Nesse sentido, faz-se mister um estudo cuidadoso sobre o papel do Estado como agente regulador das atividades econômicas e das ações antrópicas voltadas à implementação de práticas ambientalmente sustentáveis. A questão que se coloca é: os governantes estão preparados, da perspectiva técnica e ética, para, efetivamente, pôr em prática as normas ambientais plasmadas nos mais variados diplomas normativos existentes no direito brasileiro e nos tratados e convenções de que o país é signatário?

Com efeito, a ética aqui acentuada é a ética ambiental, a qual enfeixa um conjunto de princípios e regras morais que impõe uma relação de cuidado e respeito entre o homem e a natureza. Trazer a ética ambiental para o cenário político-jurídico é condição sine qua non para se aumentar o espectro das políticas públicas voltadas à prevenção de danos ambientais e, bem assim, outras formas de responsabilização civil, penal e administrativa.

Desse modo, a responsabilidade socioambiental deve alcançar não somente o ato comissivo contra o meio ambiente, mas também o ato omissivo. Tal omissão pode ser estatal ou de um particular, não importa, pois por força da norma esculpida no art. 225, da Carta Constitucional brasileira de 1988, todos têm a obrigação de proteger a natureza. Leonardo Boff ${ }^{26}$ defende a ética do cuidado, fundada em duas premissas básicas, a autolimitação e a justa medida. A primeira (autolimitação) compreende "a renúncia necessária que fazemos de nossos desejos e da voracidade produtivista e consumista para salvaguardar a integridade e a sustentabilidade de nosso planeta"; de tal sorte que a ética do cuidado para com o ecossistema deva ser o mote do agir humano.

25 Ana Alice De Carli, A água e seus instrumentos de efetividade, op. cit.

26 Leonardo Boff, Cuidar da terra, proteger a vida, op. cit. 
Por sua vez, a justa medida (a segunda premissa apontada por Leonardo Boff) "está na base de todas as virtudes, porque a justa medida é o ótimo relativo, o equilíbrio entre o mais e o menos". Esse equilíbrio no que diz respeito às ações humanas com impacto negativo no meio ambiente exige um exercício de cidadania ecológica, somado à vontade de mudar padrões de conduta.

No cenário das águas, mudanças de hábitos e comportamentos, somadas à necessidade de se buscar a sustentabilidade dos usos consuntivos (ocorre a redução significativa do potencial de água), são necessárias, especialmente em um contexto no qual a demanda por bens e serviços cresce vertiginosamente impondo ao Estado ações que conjuguem planejamento e gestão séria. Isso especialmente quando se verifica que, no mundo contemporâneo, em paralelo ao crescimento da economia, da ciência e da tecnologia, ampliam-se os causadores de poluição e seus nefastos efeitos.

A dificuldade de se concretizar universalmente o direito fundamental à água esbarra em vários fatores; um deles, como já apontado, é a falta de planejamento, mas há outros que impactam sobremaneira impedindo que tal direito tenha efetividade plena, que são a poluição, o uso irracional e a escassez hídrica.

Saindo um pouco do contexto brasileiro, em Luanda, no Estado de Angola, é comum encontrar pelas ruas pessoas vendendo água supostamente limpa em saquinhos plásticos por 10 centavos de dólar. Em 2006, o consumo de águas poluídas na região resultou em um dramático processo de epidemia de cólera, levando ao óbito cerca de 80 mil angolanos, esclarece Thomas Havisham. ${ }^{27}$

Em Nova Délhi, na Índia, o acesso à água tornou-se conquista diária para seus moradores, que acordam ávidos por encontrar o precioso líquido. Nesse cenário, descreve o astrólogo indiano Kamal Bhate, citado por Brook Larmer, ${ }^{28}$ "acordamos todos os dias lutando pela água". Para tentar demonstrar o problema enfrentado diariamente pelos indianos, Brook Larmer ${ }^{29}$ relata a realidade vivida por uma mulher de 25 anos, chamada Chaya, casada e mãe de cinco filhos, cujo trecho da história merece realce:

27 HAVISHAM, Thomas. National Geographic Brasil. Edição Especial: água o mundo tem sede, São Paulo, a. 10, n. 121, p. 78, 2010.

28 LARMER, Brook. Calor no Himalaia. National Geographic Brasil, op. cit., p. 84-101.

29 Ibid., p. 84-101. 
O dia de Chaya [...] começou antes do amanhecer, quando ela e os cinco filhos se espalharam na escuridão armados de vasilhames plásticos de vários tamanhos. Após clarear, o rumor de que havia uma bica com água corrente a fizera sair em louca disparada pelas estreitas travessas da favela [...]. Uma gritaria irrompe: é um caminhão pipa. Chaya, num pulo, junta-se à torrente humana. Uma dúzia de rapazes introduz mangueiras no tanque e começa a extrair água. Embaixo, mulheres aos berros empurram-se para encher seus vasilhames. Em seis minutos o tanque se esvazia. Chaya chega tarde e só lhe resta esperar pelo próximo rumor da remessa de água.

O autor em tela revela que a pobre mulher só conseguiu ter acesso à água na parte da tarde daquele dia, quando uma bica de água, "milagrosamente", resolveu pingar o precioso líquido; de tal modo que Chaya pôde, até que enfim, realizar o sonho de encher seu vasilhame de 40 litros de água suja e amarga. Em claro desabafo, justifica a mulher: "eles [os filhos] deviam estar estudando, mas temos sempre de botá-los para correr em busca de água [...]. Não temos escolha", finaliza.

A história descrita poderia ser cena de um filme de ficção - o que já seria suficiente para emocionar até aquela pessoa mais difícil de demonstrar sentimentos de compaixão -, mas, infelizmente, não se trata de produção cinematográfica ou de obra de ficção, mas de dura realidade.

A guerra pelo líquido precioso parece já ter começado em alguns lugares do mundo, onde a escassez do ouro azul castiga o corpo e a alma de todas as pessoas indiscriminadamente, sejam elas crianças, homens e mulheres, jovens e idosos, além dos animais e do próprio ecossistema. Nesse cenário de "guerra", o espírito de solidariedade perambula sem luz, pelas ruelas pobres e carentes de água de muitos lugares, assim como na história narrada por Brook Larmer.

Sem descuidar de mencionar que o ouro azul também tem sido utilizado como instrumento de guerra. Vanessa Barbosa ${ }^{30}$ revela que na Síria o conflito pela água perdura há mais de três anos, tendo como consequência a morte de 150 mil pessoas, e a existência de um quantitativo de 9 milhões de refugiados.

30 BARBOSA, Vanessa. A água está virando arma de guerra. Exame. Disponível em: <http:// exame.abril.com.br/mundo/noticias/conflito-liquido-como-a-agua-esta-virando-arma-deguerra>. Acesso em: 15 maio 2015. 
Aponta ainda a jornalista outros exemplos, nos quais a água não tem sido usada com fins éticos ou lúdicos:

Na década de 80, durante a guerra Irã-Iraque, o Irã desviou água para inundar as defesas militares do Iraque.

Na Guerra do Golfo (1990-1991), o Iraque bombardeou as plantas de dessalinização no Kuwait, destruindo boa parte da capacidade de produção de água potável do país.

Mais tarde, em 1993, Saddam Hussein drenou e envenenou o Marismas da Mesopotâmia, que garantia o suprimento de água dos árabes que se escondiam nos pântanos.

Até mortos já foram usados para contaminar água. Na guerra do Kosovo (1996-1999), os sérvios jogaram cadáveres em poços de suprimento em Kosovo.

Diante dos maus exemplos anteriormente referidos reforça-se a necessidade de se discutir o papel e a importância da ética ambiental pari passu à ampliação do escopo das responsabilidades civis, penais e administrativas. Por oportuno, vale mencionar a proposta da ativista ambiental Polly Higgins, do Movimento Eradicating Ecocide, o qual busca, junto à ONU, o reconhecimento do crime de ecocídio. Tal crime é definido na proposta do referido movimento como: ${ }^{31}$

the extensive damage to, destruction of or loss of ecosystem(s) of a given territory, whether by human agency or by other causes, to such an extent that - (1) peaceful enjoyment by the inhabitants has been severely diminished; and or (2) peaceful enjoyment by the inhabitants of another territory has been severely diminished. ${ }^{32}$

Sem querer adentrar a polêmica em torno do mencionado tipo penal, cabe, no entanto, realçar a importância de se problematizar a temática das

31 HIGGINS, Poly. Ecocide act. Disponível em: <http://eradicatingecocide.com/>. Pesquisa realizada em: 15 maio 2015

32 Tradução livre: extensivo dano, destruição ou perda de ecosistemas de um determinado território, seja por intervenção humana ou por outras causas, a tal ponto que: 1. O gozo pacífico pelos moradores se torna severamente reduzido; e ou 2. a pacífica fruição pelos habitantes de outro território acaba sendo severamente reduzida. 
diversas formas de responsabilidade, seja no âmbito interno de cada país, seja extramuros, envolvendo a proteção e a preservação do meio ambiente e de seus bens naturais, a exemplo das águas.

O Brasil também não fica incólume de problemas e conflitos quando o assunto é a água. Especialmente na atualidade, na qual é possível afirmar que o país enfrenta uma "crise da água", malgrado deter cerca de $12 \%$ do total de água doce existente no planeta. Na região do estado de São Paulo, um dos principais sistemas hídricos, o Cantareira (formado por cinco bacias hidrográficas; áreas onde há recurso hídrico para captação), está em colapso. Para se ter uma ideia da gravidade, sua capacidade hídrica no dia 17 de outubro de 2014 chegou ao patamar de 3,9\%, segundo informações da Companhia de Saneamento Básico do Estado de São Paulo (Sabesp). Com efeito, o problema de escassez de água não é recente no Brasil. A Região Nordeste do país convive com essa dura realidade há séculos, pois, além de deter apenas $3 \%$ do total de recursos hídricos existentes no território, possui um conjunto de rios intermitentes, longos períodos de seca e altas temperaturas quase o ano todo, o que contribui para o aumento do processo de evaporação do líquido precioso. ${ }^{33}$

José Roberto Nalini ${ }^{34}$ assevera que a água representa o "elo que vincula todas as coisas vivas, tão vital para a sobrevivência como o próprio ar". Nessa perspectiva, é preciso enfatizar os elementos fundamentalidade e essencialidade da água, como critério de adoção de políticas de proteção e preservação deste líquido vital, sem olvidar de garantir a todos o mínimo existencial. Sobre esse conceito, afirma Ricardo Lobo Torres: ${ }^{35}$

A proteção ao mínimo existencial, sendo pré-constitucional, está ancorada na ética e se fundamenta na liberdade, ou melhor, nas condições iniciais para o exercício da liberdade, na ideia de felicidade, nos direitos humanos e nos princípios da igualdade e da dignidade humana [...].

Ainda sobre o mínimo existencial, Ingo Wolfgang Sarlet ${ }^{36}$ pondera que, a despeito de inexistir norma constitucional expressa, é possível visualizá-lo

\footnotetext{
Ana Alice De Carli, Água é vida, op. cit.

34 NALINI, José Renato. Ética ambiental. 3. ed. Campinas, SP: Millennium, 2010. p. XI.

5 TORRES, Ricardo Lobo. O direito ao mínimo existencial. Rio de Janeiro: Renovar, 2009. p. 13.

36 SARLET, Ingo Wolfgang. Mínimo existencial e direito privado: apontamentos sobre algumas dimensões da possível eficácia dos direitos fundamentais sociais das relações jurídico-privadas. In: DE SOUZA NETO, Cláudio Pereira; SARMENTO, Daniel. A constitucionalização do direito: fundamentos teóricos e aplicações específicas. Rio de Janeiro: Lumen Juris, 2007. p. 336-337.
} 
"nos próprios direitos sociais específicos (como a assistência social, a saúde, a moradia, a previdência social, o salário mínimo dos trabalhadores, entre outros)". Entre esses "outros", a que se refere o autor em tela, podem-se incluir os direitos ao acesso à água com qualidade e aos serviços de esgoto, por certo.

A rigor, diversos são os argumentos que podem fundamentar a tese segundo a qual a água consubstancia direito fundamental. Nesse sentido, Luciana Cordeiro de Souza ${ }^{37}$ apresenta uma série de aspectos que corroboram a referida tese; veja-se: a) a água como elemento essencial à sobrevivência das pessoas, da fauna e da flora; b) a água como requisito essencial ao desenvolvimento de coletividades que se agrupam próximo de rios e mares; c) a água como elemento simbólico de crenças; d) a água como matéria-prima para produção de alimentos, bebidas, remédios, cosméticos etc.; e) a água como forma de lazer; f) a água como via de acesso para pessoas e cargas, promovendo a globalização e o processo de hibridação, ${ }^{38}$ além de outras funções.

Nesse sentido, apregoa-se a possibilidade de o constituinte derivado, por meio de emenda à Constituição, incluir no Capítulo I, do Título II, que trata dos Direitos e Garantias Fundamentais, os direitos ao acesso à água potável e ao sistema de tratamento de esgoto, e, ainda, estabelecer em capítulo próprio $\mathrm{o}$ direito das águas (o qual será examinado adiante). ${ }^{39}$

Com efeito, tramita no Congresso Nacional, desde 2007, uma Proposta de Emenda à Constituição, de autoria do deputado federal do estado do Ceará, Raimundo Gomes de Matos, cujo objeto é a inserção do direito à água no rol dos direitos sociais, os quais estão insculpidos no art. $6^{0}$ da Constituição Federal de $1988 .^{40}$

CORDEIRO, Luciana de Souza. Águas e sua proteção. Curitiba: Juruá, 2006. p. 13-14.

38 A propósito, a noção de hibridação, trazida por Nestor Garcia Canclini, enfeixa em si uma série de fenômenos que se interconectam e, muitas vezes, se contradizem. Aliás, como acentua o mencionado autor, "a hibridação não é sinônimo de fusão sem contradições, mas, sim, que pode ajudar a dar conta de formas particulares de conflito geradas na interculturalidade recente em meio à decadência de projetos nacionais de modernização da América Latina". In: CANCLINI, Néstor Garcia. Culturas híbridas. Estratégias para entrar e sair da modernidade. Tradução de Ana Regina Lessa e Heloisa Pezza Cintrão; tradução da Introdução de Gênese Andrade. São Paulo: USP, 2001. p. XIX.

39 Sobre o assunto, vide Ana Alice De Carli, A água e seus instrumentos de efetividade, op. cit. e id., Água é vida, op. cit.

40 BRASIL. Poder Legislativo. Câmara dos Deputados. Proposta de Emenda à Constituição $n^{\text {o }}$ 39/2007. Disponível em: <www.camara.gov.br>. Acesso em: 1o out. 2011. Ressalte-se que a proposta em tela foi arquivada, em 31 de janeiro de 2011, pela Presidência da Câmara dos Deputados, por força do art. 105, do Regimento Interno desta Casa Legislativa, que dispõe, in verbis, "art. 105. Finda a legislatura, arquivar-se-ão todas as proposições que no seu decurso tenham sido submetidas à deliberação da Câmara [...]". Mas, em razão de requerimento 
Nessa linha de preleção, parece incontestável o reconhecimento da natureza jurídica de direito fundamental à água. Também é defensável juridicamente sua essência de sujeito de direito, conforme será examinado no capítulo seguinte, do direito das águas.

\section{3. $\mathrm{O}$ direito das águas}

Neste momento tem-se por desiderato tratar da possibilidade de a natureza e, por conseguinte, de a água serem sujeitos de direitos. Em paralelo, procurase demonstrar dois aspectos indissociáveis à defesa da tese de que a natureza pode ser sujeito de direitos: $o$ primeiro está relacionado com a necessidade premente de aproximar a visão antropocêntrica da perspectiva ecocêntrica, a fim de se construir uma nova relação entre o homem e a natureza. O segundo elemento diz respeito à ideia de que é sujeito de direitos quem o direito assim o intitula, da mesma forma que o fez com a pessoa jurídica, considerando a relevância do bem a ser tutelado.

Nas palavras do biólogo inglês James Lovelock, ${ }^{41}$ a terra possui alma, anima mundi. Tal linha de pensamento, no entanto, não é oriunda da modernidade, a exemplo da corrente denominada de Ecologia Profunda (Deep Ecology) ${ }^{42}$ capitaneada pelo filósofo norueguês Arne Naess, tampouco da Teoria de Gaia, defendida por James Lovelock ${ }^{43}$ - entre outros -; ao revés, tal pensamento remonta à Antiguidade, quando os povos tradicionais (aqui incluídos os indígenas) visualizavam a terra como mãe, que concebia a vida. Stephan Harding ${ }^{44}$ esclarece que, na Grécia Antiga, onde a terra era chamada de Gaia, acreditava-se no anima mundi, que, complementa o autor, "habitava as grutas subterrâneas de Delfos e Atenas e falava diretamente com as sacerdotisas intoxicadas pelos vapores exalados dos profundos orifícios no útero da mãe Terra".

de desarquivamento, por parte do autor da proposta de emenda à Constituição no 39/2007, o deputado Raimundo Gomes de Matos, em 17 de fevereiro de 2011, a Mesa Diretora da Câmara dos Deputados deferiu o pedido de desarquivamento. Agora cabe aguardar a boa vontade dos parlamentares brasileiros.

41 Leonardo Boff, Cuidar da terra, proteger a vida, op. cit., p. 33.

42 Naess, 1990 apud HARDING, Stephan. Terra viva: ciência, intuição e a evolução de gaia. Tradução de Mario Molina. São Paulo: Cultrix, 2008.

43 Leonardo Boff, Cuidar da terra, proteger a vida, op. cit., p. 37.

44 Stephan Harding, Terra Viva, op. cit., p. 79-81. 
Na Idade Moderna, alguns estudiosos têm resgatado a visão clássica de que a terra não só é um ser vivo como também concebe vida. Nesse sentido, Stephan Harding, ${ }^{45}$ inspirado no pensamento do filósofo clássico grego Demócrito, ${ }^{46}$ faz uma analogia entre os elementos químicos, os átomos e os elementos humanos. Segundo o autor:

O mundo material é realmente constituído de átomos [...], os átomos não são entidades mortas, mecânicas; são seres participativos com características aparentadas às nossas, embora as dos átomos sejam muito mais consistentes que a natureza humana, que é maleável, frequentemente imprevisível e muito dependente de circunstâncias.

As questões ambientais exigem, além de uma visão holística, associada a vários saberes, uma percepção sensorial. Esta defendida pelo filósofo e ecologista americano da contemporaneidade David Abram, ${ }^{47}$ cuja experiência, relatada por Stephan Harding, ${ }^{48}$ merece ser resumida, para elucidar a importância do aspecto sensorial no estudo das águas.

Certo dia, fazendo uma escalada numa ilha da Indonésia, Abram ficou inesperadamente encurralado numa gruta pelo primeiro aguaceiro torrencial da estação das monções [...]. Uma pequena aranha que tecia uma delicada teia pela entrada da gruta despertou sua atenção [...]. Isso o levou a concentrar o olhar, o que o fez subitamente descobrir que havia numerosas outras aranhas moldando suas estruturas em espiral [...]. A intrincada atividade das aranhas o colocou mais profundamente em êxtase; ele logo descobriu que não conseguia mais ouvir o ronco da torrente da cascata, bem atrás das teias que se expandiam [...]. Ao descer da gruta, descobriu que não era mais capaz de ver qualquer

45 Ibid., p. 107-108.

46 Vide MARÍAS, Julián. História da filosofia. Tradução de Claudia Berliner. São Paulo: Martins Fontes, 2004. p. 36-37. Demócrito foi um dos últimos pré-socráticos e defendia a teoria de que tudo era formado por átomos, "inclusive a alma". Explica o autor que, para Demócrito, "a percepção se realiza do seguinte modo: as coisas emitem uma espécie de espectros ou imagens sutis, compostos por átomos mais finos, que penetram nos órgãos dos sentidos. Assim, a mente recebe uma cópia ou réplica da coisa, e nisso consiste o conhecimento; trata-se, portanto, de uma doutrina sensualista".

47 Abram, 1997 apud Stephan Harding, Terra Viva, op. cit., p. 57-58.

48 Stephan Harding, Terra Viva, op. cit., p. 58-59. 
aspecto do mundo como uma presença inerte ou inanimada: mesmo as pedras e os penhascos estavam cintilantes.

A experiência vivida pelo filósofo David Abram, por certo, instiga reflexão necessária sobre os problemas ambientais na atualidade. A natureza, em especial no presente texto, as águas, clama por cuidados e, nesse sentido, as mudanças climáticas, o crescimento exponencial de elementos poluidores e da demanda dos seus mais variados usos e, bem assim, sua escassez, respaldam uma pergunta que impõe providências urgentes: até quando a humanidade vai omitir-se no tratamento e cuidados necessários com a terra? Em particular com as águas?

Nesse contexto, com base nos dados do Painel Intergovernamental sobre Mudanças Climáticas de 2007 (IPCC), que traz a lume o significativo aumento de clorofluorcarbonetos, ${ }^{49}$ entre outras substâncias poluidoras e, com fundamento na Teoria de Gaia, a qual defende que a terra se autorregula, Leonardo Boff $^{50}$ vaticina que a natureza pode desenvolver formas de adaptação; todavia, tais mecanismos de defesa podem não ser benéficos para a humanidade. Alguns estudiosos ${ }^{51}$ acreditam, inclusive, na possibilidade de o superorganismo-terra pôr fim à própria espécie humana, assim como ocorreu com outros seres vivos, a exemplo dos animais do Período Cambriano, pertencentes à denominada Era Paleozoica, ${ }^{52} \mathrm{e}$ dos dinossauros, há milhões

49 TELLES, Dirceu D'Alkmin; COSTA, Regina Pacca (Coord.). Reúso da água: conceitos, teorias e práticas. 2. ed. São Paulo: Blucher; FAT., 2010. p. 365-366. Conforme explicam os autores, o clorofluorcarbono (CFC) "é um composto químico gasoso, cuja molécula é composta de átomos dos elementos cloro, flúor e carbono [...]. Constitui um gás de alto poder refrigerante, por isso muito usado na indústria (geladeiras e condicionadores de ar). Também constitui um dos principais componentes na produção de espuma, como as caixinhas de sanduíches em lanchonetes [...]." Conforme esclarecem os pesquisadores, devido aos prejuízos que tal composição causa à camada de ozônio, alguns programas têm sido desenvolvidos no sentido de acabar com a utilização do clorofluorcarbono pela indústria. Segundo eles, na atualidade, algumas indústrias de geladeiras e outros produtos já estão dispensando o uso deste composto químico.

50 Leonardo Boff, Cuidar da terra, proteger a vida, op. cit., p. 37.

51 LOVELOCK, James E. A vingança de Gaia. Rio de Janeiro: Intrínseca, 2006. p. 245-246.

52 Conforme dados do Serviço Geológico do Brasil, "nesse período, aconteceu a maior diversificação da vida, evento conhecido como explosão cambriana, pois ocorreu num intervalo de tempo relativamente curto. Além de animais de corpo mole, surgem, no mar, outros, com carapaças duras, alguns com pernas e outros apêndices. Foi quando apareceu a maioria dos principais grupos de animais, entre eles os anelídeos, artrópodes, braquiópodes, equinodermos, moluscos e esponjas. O domínio era dos trilobitas (extintos no Permiano) e dos braquiópodes. Os vegetais eram representados por algas marinhas apenas. A Terra não tinha, portanto, cobertura vegetal". Vide COMPANHIA DE PESQUISA DE RECURSOS MINERAIS (CPRM). Disponível em:<www.cprm.gov.br>. Acesso em: 24 set. 2011. 
de anos. Refletindo acerca da ideia do possível fim da humanidade, indaga Leonardo Boff::53 "Se Gaia teve de liberar-se de milhares de espécies ao largo de sua biografia, quem nos garante que não se veja coagida a se livrar da nossa, que se mostrou antes como satã da terra do que como anjo bom?".

A rigor, muitas vidas já têm sido ceifadas por conta do descaso com o meio ambiente; conforme explicita o Relatório do desenvolvimento humano de 2006, do Programa das Nações Unidas para o Desenvolvimento (PNUD), ${ }^{54}$ a água poluída é a segunda maior causadora de mortes de crianças em todo o mundo.

Acredita-se que o direito pode ajudar a mudar esta realidade. Assim, admitindo-se essa premissa, cabe à ciência jurídica, dentro de sua seara normativa transformadora e modeladora do mundo da vida, desenvolver metodologia que eleve a natureza e, por conseguinte, a água à categoria de sujeitos de direitos; da mesma forma que, de uma perspectiva ficcional, transformou as sociedades negociais em pessoas jurídicas, vale dizer, em sujeitos de direitos.

As relações jurídicas tradicionais triangulares, em que há, pelo menos, uma pessoa (natural ou jurídica) em cada polo e um objeto no meio que as vincula, devem ser reavaliadas, com o fito de coadunar-se à concepção de meio ambiente natural como sujeito de direitos.

No tocante à tese da existência de direitos da natureza, por oportuno, merece especial realce o pioneirismo da Constituição da República do Equador de $2008^{55}$ que, em seu art. 71, estabelece tais direitos:

\section{Derechos de la naturaleza}

Art.71. - La naturaleza o Pacha Mama, donde se reproduce y realiza la vida, tiene derecho a que se respete integralmente su existencia y el mantenimiento y regeneración de sus ciclos vitales, estructura, funciones y procesos evolutivos.

53 Leonardo Boff, Cuidar da terra, proteger a vida, op. cit., p. 37.

54 PROGRAMA DAS NAÇÕES UNIDAS PARA O DESENVOLVIMENTO (PNUD). Relatório do desenvolvimento humano de 2006. Disponível em: <www.ipad.mne.gov>. Acesso em: 22 set. 2011.

55 CONSTITUIÇÃO DA REPÚBLICA DO EQUADOR de 28 de setembro de 2008. Disponível em: <www.mmrree.gob.ec>. Acesso em: 20 set. 2011. Tradução livre: "Art. 71. A natureza ou Pacha Mama, de onde a vida se reproduz e se realiza, tem o direito ao respeito absoluto de sua existência bem como de sua preservação e regeneração de seus ciclos vitais, sua estrutura, funções e processos de evolução. Toda pessoa, comunidade, povo ou nacional poderá exigir das autoridades públicas o cumprimento dos direitos da natureza. Para aplicar e interpretar tais direitos, devem ser observados os princípios estabelecidos na Constituição. O Estado incentivará as pessoas naturais e jurídicas, e as coletividades, para que protejam a natureza, bem como promoverá o respeito de todos os elementos que formam o ecossistema". 
Toda persona, comunidad, pueblo o nacionalidad podrá exigir a la autoridad pública el cumplimiento de los derechos de la naturaleza. Para aplicar e interpretar estos derechos se observaran los princípios establecidos en la Constitución, en lo que proceda. El Estado incentivará a las personas naturales y jurídicas, y a los colectivos, para que protejan la naturaleza, y promoverá el respeto a todos los elementos que forman un ecosistema.

Ainda, o economista equatoriano Alberto Acosta ${ }^{56}$ propugna a construção de uma Declaração Universal dos Direitos da Natureza, argumentando:

Al reconocer a la Naturaleza como sujeto de derechos, en la búsqueda de ese necesario equilibrio entre la Naturaleza y las necesidades y derechos de los seres humanos, enmarcados en el principio del Buen Vivir, se supera la clásica versión jurídica. Y para conseguirlo nada mejor que diferenciar los Derechos Humanos de los Derechos de la Naturaleza, tal como lo plantea Gudynas. ${ }^{57}$

Na trilha de Alberto Acosta, reconhece-se a necessidade de releitura de alguns institutos do direito, com vistas a criar condições à defesa da tese de que a natureza pode ser sujeito de direitos.

Da Declaração universal dos direitos da água, ${ }^{58}$ da ONU, de 1992,, ${ }^{59}$ é possível extrair os fundamentos que embasam a tese da possibilidade de existência da categoria fundamental de direitos das águas, estas como sujeitos de direitos. Nessa perspectiva, o homem ocuparia duas posições distintas: a de predador e a de defensor das águas. Para ilustrar, transcreve-se excertos do citado documento:

56 ACOSTA, Alberto. Declaración universal de los derechos de la naturaleza. Disponível em: <www. derechosdelanaturaleza.com>. Acesso em: 21 set. 2011.

57 Tradução livre: "Ao se reconhecer a Natureza como sujeito de direitos, busca-se o necessário equilíbrio entre a Natureza e as necessidades e os direitos das pessoas humanas, fundados no princípio do bem-viver, o que impõe a superação da visão clássica de relação jurídica. Isso pode ser conseguido diferenciando os direitos humanos dos direitos da natureza, tal como defende Gudynas".

58 DECLARAÇÃO DOS DIREITOS DA ÁGUA. Disponível em: <www.ecolnews.com.br>. Acesso em: 23 dez. 2010

59 Dia 22 de março de 1992 é considerado, de acordo com a ONU (Organização das Nações Unidas), o "Dia Mundial da Água", o qual vem sendo celebrado por Estados, Organizações governamentais e não governamentais, outros segmentos sociais, além de pesquisadores e acadêmicos em geral. 
[...] 7. A água não deve ser desperdiçada, nem poluída, nem envenenada. De maneira geral, sua utilização deve ser feita com consciência e discernimento para que não se chegue a uma situação de esgotamento ou de deterioração da qualidade das reservas atualmente disponíveis. 8.-A utilização da água implica em respeito à lei. Sua proteção constitui uma obrigação jurídica para todo homem ou grupo social que a utiliza. Esta questão não deve ser ignorada nem pelo homem nem pelo Estado.

9.-A gestão da água impõe um equilíbrio entre os imperativos de sua proteção e as necessidades de ordem econômica, sanitária e social. [grifo nosso]

Considera-se extremamente relevante elevar a água à categoria de sujeito de direitos e de dignidade, bem como positivos os efeitos daí decorrentes. A primeira consequência é a conscientização de que a água precisa de cuidados especiais, no tocante aos seus aspectos quantitativo e qualitativo. Outro efeito esperado é de o homem imaginar-se no lugar da natureza e avaliar como se sentiria se alguém invadisse seu habitat sem o mínimo pudor ou respeito.

Da perspectiva jurídica, a consequência de elevar a água ao status de sujeito de direito seria o fato de que qualquer pessoa poderia tutelá-la, além da possibilidade de manejar os instrumentos constitucionais processuais, para defendê-la. A Carta Constitucional de 1988, em seu art. 5o, LXXIII, consagra, por exemplo, a Ação Popular como instrumento à disposição de qualquer cidadão para repelir ato lesivo ao meio ambiente, sem prejuízo de outras garantias e instrumentos jurídicos.

Sem dúvida, o direito das águas surge em um contexto no qual a natureza clama por socorro e a humanidade precisa despertar para salvar a si mesma e o planeta Terra. Defender o direito das águas significa dar um passo à frente rumo à preservação e ao respeito ao meio ambiente.

Apesar dos avanços no que diz respeito à conscientização ambiental, a humanidade ainda padece de certo analfabetismo funcional, quando o assunto é meio ambiente natural. A relação do homem com o meio ambiente ainda é muito calcada em uma visão utilitarista, na trilha do que defendiam Francis Bacon, Galileu e René Descartes, nos séculos XVI e XVII, segundo a qual a natureza existe para satisfazer as vontades e necessidades do homem; ou seja, é mero objeto. ${ }^{60}$

60 DESCARTES, René. Discurso do método. Tradução de João Cruz Costa. São Paulo: Tecnoprint, 1958. p. 130-131. Conforme se infere de suas palavras, não há nenhum sinal aparente de que ele 
Nessa toada, entende-se de extrema relevância jurídica, ética e socioambiental o reconhecimento expresso no texto da Constituição Federal de 1988 do direito à água, pari passu o direito ao saneamento básico, no capítulo dos direitos e garantias fundamentais, e do direito das águas, em capítulo próprio ou inserido no capítulo, já existente, do meio ambiente. Isso tudo com o propósito de: despertar a cidadania ecológica nos homens; criar elementos para o nascimento de uma nova relação entre o homem e a natureza, fundada no respeito e na igualdade; e, ainda, ampliar o escopo de proteção das águas brasileiras, aumentando o número de seus tutores, porquanto ao lado do Estado estariam também os cidadãos.

Sem a pretensão de esgotar o tema dos direitos das águas, busca-se no capítulo seguinte perfilar alguns aspectos do direito de águas, cuja vinculação com os direitos à água e das águas é intrínseca.

\section{Direito de águas}

A partir do pressuposto de que o direito é, ao mesmo tempo, um instrumento por meio do qual o homem, politicamente civilizado, orienta sua conduta na busca do equilíbrio das relações e uma função social, no sentido de que desempenha os papéis de criador e transformador da realidade, examinarse-á agora a importância desse instituto jurídico no processo de gestão das águas, bem como para o fomento de uma cultura social voltada para o uso racional dessa riqueza. Nesse diapasão, vaticina Jerson Kelman:61 "ter água é hoje um diferencial para uma Nação ser uma potência econômica e social".

Pode-se afirmar que a reaproximação do homem com a natureza ocorreu, ainda que timidamente, a partir da Declaração da Convenção das Nações Unidas para o Meio Ambiente, ${ }^{62}$ realizada em Estocolmo, em 1972. Nesse contexto,

defendia o uso irracional e irresponsável dos recursos naturais. Ademais, naquela época ainda não havia o processo de industrialização em massa, que trouxe, apesar do desenvolvimento econômico, desigualdades sociais e poluição ambiental. O contexto era outro, os fatores de poluição não alcançavam a gravidade dos existentes hoje. O problema que se enfrenta é que o contexto mudou, mas parece que o homem contemporâneo continua preso ao pensamento dos séculos XVI e XVII no tocante à natureza.

61 KELMAN, Jerson. Entrevista concedida à jornalista Mônica Pileggi, em artigo intitulado "o fator água". National Geographic Brasil. Edição Especial: Água, o mundo tem sede, São Paulo, a. 10, n. 121, p. 47-50, 2010.

62 FINK, Daniel R. Relação jurídica ambiental e sustentabilidade. In: MARQUES, José Roberto (Org.). Sustentabilidade e temas fundamentais de direito ambiental. Campinas, SP: Millennium, 2009. p.101-120. Apregoa o autor: "a transformação da vida social implica a própria transformação 
merece menção a quarta diretriz do referido documento, ${ }^{63}$ que dispõe textualmente:

O homem tem a responsabilidade especial de preservar e administrar ponderadamente o patrimônio representado pela flora e pela fauna silvestres, bem como pelo seu habitat, que se encontram atualmente em grave perigo, em virtude da conjugação de diversos fatores. Consequentemente, ao se planejar o desenvolvimento econômico, deve atribuir-se uma importância específica à conservação da natureza, aí incluídas a flora e a fauna silvestres. [sem grifo no original]

Conforme se depreende da referida diretriz, a preocupação com a questão da responsabilidade socioambiental do homem não deve - e não pode - restringir-se à seara dos ambientalistas, biólogos, químicos, geólogos, ecologistas, hidrólogos e outros tantos estudiosos e pesquisadores que dedicam parcela de seu tempo para cuidar de assuntos relacionados com o planeta Terra - profissionais cujas vozes, durante décadas, soaram apenas como sussurros aos ouvidos dos demais atores sociais - , eis que as questões ambientais, por longo tempo, foram preteridas em favor de interesses patrimoniais até mesmo na seara do direito.

Brook Larmer ${ }^{64}$ ilustra o quadro da responsabilidade social com a história (real) de um lavrador do Tibet, chamado Jia Son, que, ao constatar in loco o derretimento das geleiras do Himalaia, ${ }^{65}$ refletiu - sentindo-se também responsável - acerca da necessidade de o homem agir, independentemente da grandeza de sua ação, no sentido de proteger o que ainda resta daquele ecossistema. Nesse cenário, o lavrador, ao olhar a multidão de turistas que contemplavam a beleza monumental das geleiras, desabafou "nada vai mudar, enquanto não nos livrarmos da mentalidade materialista". ${ }^{66} \mathrm{Na}$ verdade, o materialismo faz parte do viver humano, mas o que se infere do pensamento

do Estado e seu papel, seja como agente indutor de políticas de desenvolvimento, seja como regulador das várias novas implicações que tais políticas acarretam na vida das pessoas".

63 ORGANIZAÇÃO DAS NAÇÔES UNIDAS. Disponível em: <www.un.org>. Acesso em: 24 dez. 2010

64 Brook Larmer, Calor no Himalaia, op. cit., p. 101.

65 Estudos apontam que, nos últimos 50 anos, das 680 geleiras controladas por cientistas no planalto tibetano, cerca de $95 \%$ estão degelando em percentual maior do que acumulando gelo. Vide ibid., p. 92.

66 Relata Brook Larmer que Jia Song, em uma ação do governo, deixou parte de suas terras para reflorestamento. 
do personagem real apresentado por Brook Larmer é que não se pode, em nome de um querer a qualquer custo, destruir o habitat natural em que se vive, ou, ainda, privilegiar o interesse econômico, em detrimento da preservação ambiental.

A partir da história do lavrador tibetano, cabe uma reflexão acerca da relevância socioambiental do direito para disciplinar os usos das águas.

$\mathrm{O}$ direito de águas está escorado em um complexo sistema de regras e princípios que rege a forma pela qual se desenvolve a gestão dos recursos hídricos, aqui compreendidos especificamente os mananciais de água doce. A propósito, as águas doces, em solo brasileiro, recebem, muitas vezes, tratamento jurídico distinto, considerando suas características ou as formas de uso. Nesse sentido, tem-se, à guisa de ilustração: ${ }^{67}$

a. Água canalizada: aquela fornecida por aqueduto diretamente pelo Estado ou por prestadora de serviço público. Sua disciplina normativa tem como fundamento a dimensão de direito fundamental, sendo a Constituição Federal de 1988 sua norma maior, seguida pela Lei Nacional das Águas (Lei no 9.433/1997), a qual prevê vários instrumentos jurídico-econômicos para a gestão do líquido precioso, a exemplo da outorga do direito de uso de recursos hídricos.

b. Água mineral envasada: recebe tratamento jurídico diverso da água canalizada, sendo disciplinada pelo Código de Águas Minerais e pelo Código de Minas, além de receber tratamento de mercadoria, não consubstanciando, em regra, um direito fundamental, podendo incidir, inclusive, o tributo estadual, imposto sobre operações relativas à circulação de mercadorias e sobre prestações de serviços de transporte interestadual e intermunicipal e de comunicação (ICMS), previsto no art. 155, inciso II, da Carta Constitucional brasileira de 1988. Com efeito, o Supremo Tribunal Federal já se manifestou no sentido de que a água mineral envazada é mercadoria. ${ }^{68}$

c. Recursos hídricos para fins de geração de energia: o art. 20, da Constituição Federal de 1988, estabelece que:

Art. 20. São bens da União:

$[\ldots]$

\footnotetext{
67 Vide DE CARLI, Ana Alice. Água, um líquido vital em busca de reconhecimento como sujeito de direitos e titular de dignidade. Revista Jurídica da Procuradoria-Geral do Distrito Federal, Brasília, v. 39, n. 2, p. 73-92, jul./dez. 2014.
}

68 Vide ADI no 2.224-5. 
VIII - os potenciais de energia hidráulica.

$\S 1^{\circ}-$ É assegurada, nos termos da lei, aos Estados, ao Distrito Federal e aos Municípios, bem como a órgãos da administração direta da União, participação no resultado da exploração de petróleo ou gás natural, de recursos hídricos para fins de geração de energia elétrica e de outros recursos minerais no respectivo território, plataforma continental, mar territorial ou zona econômica exclusiva, ou compensação financeira por essa exploração.

Os exemplos das variadas características e dos múltiplos usos das águas demonstram a necessidade de coexistência de diversificados regimes jurídicos, revelando com clareza a importância dos papéis do Estado legislador e do Estado gestor. Há de se considerar também o aspecto econômico, o qual, sem querer adentrar a discussão que gira em torno da questão da precificação da água (porquanto não é a proposta do presente texto), deve ser considerado na busca de uma gestão sustentável dos recursos hídricos.

$\mathrm{O}$ direito de águas, que consubstancia uma área específica do direito,

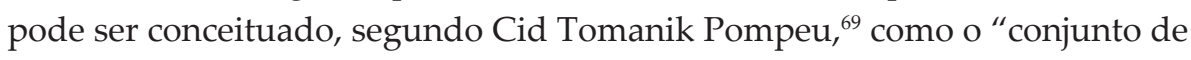
princípios e normas jurídicas ${ }^{70}$ que disciplina o domínio, o uso, o aproveitamento, a conservação e a preservação das águas, assim como a defesa contra suas danosas consequências".

$\mathrm{O}$ direito de águas encontra seu fundamento jurídico na Constituição Federal de 1988 e revela-se, respectivamente, nas leis (e seus respectivos regulamentos), nas resoluções dos órgãos de fiscalização, bem como nos tratados e acordos internacionais. Nesse sentido, merecem realce a Lei no 9.433/1997, já mencionada, as resoluções do Conama, as leis estaduais etc.

Embora a Carta Maior de 1988 não tenha sido o marco normativo das questões ambientais, deve-se atribuir a ela o mérito de promover a cidadania ecológica, ao estabelecer capítulo próprio ao Meio Ambiente - do qual a água é elemento essencial -, elevando-o, em seu art. 225, ao patamar de direito difuso e bem de uso comum de todos.

69 POMPEU, Cid Tomanik. Direito de águas no Brasil. 2. ed. São Paulo: Revista dos Tribunais, 2010. p. 43. Aponta o autor que o direito de águas também já foi denominado de direito hídrico.

70 Cabe destacar que, malgrado o autor em tela tenha feito distinção entre norma e princípio, parte da doutrina constitucionalista atribui aos princípios a qualidade de norma. Nesse sentido, cabe ver ALEXY, Robert. Teoria dos direitos fundamentais. Tradução de Virgílio Afonso da Silva. São Paulo: Malheiros, 2008. p. 87. Para o autor, a norma é o gênero, sendo princípio e regra espécies. 
Nessa toada, preleciona Diogo de Figueiredo Moreira Neto ${ }^{71}$ que a Carta de 1988 estabelece uma "tríplice inserção da água": ora como "recurso natural", ora como "elemento primário do saneamento básico" e ora como "fator ambiental". Assim, a água como "recurso natural" recebe da normativa constitucional vigente a seguinte disciplina:

a) partilha o seu domínio entre a União e os Estados (art. 20, III e art. $\left.25, \S^{\circ}\right)$;

b) atribui competência legislativa privativa (à União) para legislar sobre águas (art. 22, IV);

c) atribui competência à União para instituir o sistema nacional de gerenciamento de recursos hídricos e definir critérios de outorga de direitos de seu uso (art. 21, XIX).

A água, segundo o administrativista em tela, ${ }^{72}$ como "elemento primário do saneamento básico", recebe da Constituição Federal de 1988 o seguinte tratamento:

d) atribui competência à União para estabelecer diretrizes em nível nacional (art. 21, XX);

e) atribui implicitamente competência aos Municípios para prestar serviços de água onde prevaleça o interesse local ${ }^{73}$ (art. 30, V);

f) atribui competência aos Estados para definir regiões metropolitanas, as aglomerações urbanas e as microrregiões, nas quais deva prevalecer o interesse comum ${ }^{74}$ sobre o local (art. 25, §3ํㅡ, CF/88).

71 MOREIRA NETO, Diogo de Figueiredo. Mutações do direito administrativo. 2 ed. Rio de Janeiro: Renovar, 2001. p. 237-241.

72 Ibid., p. 241.

73 O problema é a caracterização do que seja interesse local. Conforme lições de Diogo de Figueiredo Moreira Neto, a expressão em tela veio substituir o termo peculiar interesse. Após análise doutrinária, o autor identifica o interesse local (da municipalidade) da seguinte forma: "1. predominância do local; 2 . interno às cidades e vilas; 3 . que se pode isolar; 4 . territorialmente limitado ao município; 5 . sem repercussão externa ao município; 6 . próprio das relações de vizinhança; 7. Simultaneamente oposto a regional e nacional; e 8) dinâmico". In: Diogo de Figueiredo Moreira Neto, Mutações do direito administrativo, op. cit., p. 245.

74 Explica Diogo de Figueiredo Moreira Neto que o interesse comum diferencia-se do interesse local, embora ambos tenham como núcleo o interesse público; o interesse comum, no dizer do autor, "é aquele que transcende o municipal e passa a ser considerado estadual"; apresentando algumas características peculiares: "predominância regional"; "não está territorialmente limitado ao município", "se externaliza às cidades e às vilas" etc. In: ibid., p. 246. 
Ainda de acordo com a ideia da tríplice constitucionalidade da água, tem-se o ouro azul como "fator ambiental" a que, conforme pontua o autor, ${ }^{75} \mathrm{a}$ Carta Constitucional de 1988 concede a seguinte normativa:

a) atribui competência concorrente limitada à União e aos Estados para legislar sobre a conservação de recursos naturais e meio ambiente (art. 24, I);

b) atribui aos três níveis federativos competência administrativa para proteger o meio ambiente (art. 23, VI);

c) atribui aos Estados competência para executar funções políticas de interesse comum (art. 25, §3ㅜ).

Nessa linha de pensamento, de que há na Constituição Federal "uma tríplice inserção da água", sugere-se a inclusão de mais uma perspectiva constitucional, qual seja, a água como sujeito de direitos, conforme já mencionado no capítulo 3 deste texto, sobre o direito das águas. Afinal, o direito, a partir de um paradigma de racionalidade, pode alterar o mundo da vida, quando a realidade deste mundo o exigir, por circunstâncias justificáveis, a exemplo do que ocorreu com a própria criação da figura do Estado, como pessoa jurídica e sujeito de direitos e obrigações; das pessoas jurídicas de direito privado (as sociedades, as fundações e as associações). Cada uma dessas entidades foi instituída por meio dos mecanismos da ciência jurídica para finalidades diversas.

Assim, o direito, como instituidor de regras, é fundamental para controlar e disciplinar as ações antrópicas em relação ao ouro azul. No caso, tem-se no direito de águas o(s) regime jurídico(s) delineado(s) pelo Estado, considerando as especificidades de cada região.

Ainda, vale realçar que o direito de águas, como conjunto de regras e princípios norteadores da gestão e do uso do líquido vital, é de extrema relevância sociojurídica no que diz respeito à concretização do direito fundamental de acesso à água com qualidade e, bem assim, dos direitos das águas.

75 Ibid., p. 241. 


\section{Considerações finais}

Por tudo o que foi exposto, considerando a tríplice dimensão dos direitos das águas - direito fundamental à água, direitos das águas e direitos de águas -, advoga-se a necessidade premente de se estabelecerem novos parâmetros para a construção de uma verdadeira relação de igualdade entre o homem e a natureza, isto é, uma relação de respeito e cuidado, afastando a ideia de que o meio ambiente natural é mero objeto à disposição dos interesses da humanidade. O que não significa a adoção da teoria preservacionista (desenvolvida por John Muir), que defende a quase intocabilidade da natureza. O que se visa, com fundamento na teoria conservacionista, é a harmonia entre o equilíbrio do meio ambiente e a realização das necessidades do homem, a partir de uma exploração sustentável.

Ainda, entende-se, especialmente da perspectiva didática, que o direito positivado deve reconhecer a água como sujeito de direitos e titular de dignidade, com vistas a trilhar o caminho da conscientização ambiental, coadunando-se com os objetivos da Política Nacional de Educação Ambiental (Lei nº 9.795/1999), entre os quais está "o incentivo à participação individual e coletiva, permanente e responsável, na preservação do equilíbrio do meio ambiente, entendendo-se a defesa da qualidade ambiental como um valor inseparável do exercício da cidadania" (art. 5o , inciso V) e com a Política Nacional de Recursos Hídricos (Lei no 9.433/1997), que estabelece como princípios: "assegurar à atual e às futuras gerações a necessária disponibilidade de água, em padrões de qualidade adequados aos respectivos usos; e a utilização racional e integrada dos recursos hídricos [...], com vistas ao desenvolvimento sustentável" (art. 2º).

Em síntese: sem água não há vida, nem desenvolvimento econômico!

\section{Referências}

ACOSTA, Alberto. Declaración universal de los derechos de la naturaleza. Disponível em: <www.derechosdelanaturaleza.com>. Acesso em: 21 set. 2014.

ADEDE Y CASTRO, João Marcos. Água: um direito humano fundamental. Porto Alegre: Nuria Fabris, 2008. 
BARBOSA, Vanessa. Aágua está virando arma de guerra. Exame. Disponívelem: $<$ http://exame.abril.com.br/mundo/noticias/conflito-liquido-como-a-aguaesta-virando-arma-de-guerra>. Acesso em: 15 maio 2015.

BÍBLIA SAGRADA. Livro de gênesis. Tradução de João Ferreira de Almeida. Brasília: Sociedade Bíblica do Brasil. 1990.

BOFF, Leonardo. Cuidar da terra, proteger a vida: como evitar o fim do mundo. Rio de Janeiro: Record, 2010.

BRASIL. Poder Legislativo. Câmara dos Deputados. Proposta de Emenda à Constituição $n^{0}$ 39/2007. Disponível em: <www.camara.gov.br>. Acesso em: $1^{\mathrm{o}}$ out. 2014.

CANCLINI, Néstor Garcia. Culturas híbridas. Estratégias para entrar e sair da modernidade. Tradução de Ana Regina Lessa e Heloisa Pezza Cintrão; tradução da introdução de Gênese Andrade. São Paulo: USP, 2001.

DE CARLI, Ana Alice. A água e seus instrumentos de efetividade: educação ambiental, normatização, tecnologia e tributação. São Paulo: Millennium, 2013.

Água, um líquido vital em busca de reconhecimento como sujeito de direitos e titular de dignidade. Revista Jurídica da Procuradoria-Geral do Distrito Federal, Brasília, v. 39, n. 2, p. 73-92, jul./dez. 2014.

Água é vida: eu cuido, eu poupo - para um futuro sem crise. Rio de Janeiro: Editora FGV, 2015. (FGV de Bolso, Direito e Sociedade, 39).

CORDEIRO, Luciana de Souza. Águas e sua proteção. Curitiba: Juruá, 2006.

DESCARTES, René. Discurso do método. Tradução de João Cruz Costa. São Paulo: Tecnoprint, 1958.

DECLARAÇÃO dos direitos da água. Disponível em: <www.ecolnews.com. br>. Acesso em: 23 dez. 2010.

HAVISHAM, Thomas. National Geographic Brasil. Edição Especial: água, o mundo tem sede, São Paulo, a. 10, n. 121, 2010.

HARDING, Stephan. Terra viva: ciência, intuição e a evolução de gaia. Tradução de Mario Molina. São Paulo: Cultrix, 2008.

KANT, Immanuel. A metafísica dos costumes. Tradução, textos adicionais e notas de Edson Bini. São Paulo: Edipro, 2003. 
KELMAN, Jerson. Entrevista concedida à jornalista Mônica Pileggi, em artigo intitulado "o fator água". National Geographic Brasil. Edição Especial: Água, o mundo tem sede, São Paulo, a. 10, n. 121, p. 47-50, 2010.

FINK, Daniel R. Relação jurídica ambiental e sustentabilidade. In: MARQUES, José Roberto (Org.). Sustentabilidade e temas fundamentais de direito ambiental. Campinas, SP: Millennium, 2009. p. 101-120.

HIGGINS, Poly. Ecocide act. Disponível em: <http://eradicatingecocide.com/>. Acesso em: 15 maio 2015.

LARMER, Brook. Calor no Himalaia. National Geographic Brasil. Edição Especial. Água: o mundo tem sede, São Paulo, a. 10, n. 121, p. 84-101, 2010.

LOCKE, John. Segundo tratado sobre o governo civil e outros escritos. Tradução de Magda Lopes e Marisa Lobo da Costa. 3. ed. Petrópolis: Vozes, 2001.

LOVELOCK, James E. A vingança de Gaia. Rio de Janeiro: Intrínseca, 2006.

MACHADO, Paulo Affonso Leme. Direito dos cursos de água internacionais. São Paulo: Malheiros, 2009.

MARÍAS, Julián. História da filosofia. Tradução de Claudia Berliner. São Paulo: Martins Fontes, 2004.

MELLO, Celso Antonio Bandeira de. Curso de direito administrativo. 17. ed. São Paulo: Editora Malheiros, 2004.

MOREIRA NETO, Diogo de Figueiredo. Mutações do direito administrativo. 2. ed. Rio de Janeiro: Renovar, 2001.

NALINI, José Renato. Ética ambiental. 3. ed. Campinas, SP: Millennium, 2010. OLIVEIRA, Almir de. Curso de direitos humanos. Rio de Janeiro: Forense, 2000. ORGANIZAÇÃO DAS NAÇÕES UNIDAS. Disponível em: <www.un.org>. Acesso em: 24 dez. 2014.

RUBIO, David Sánches. Repensar derechos humanos: de la anesthesia a la sinestesia. Sevilha: Mad, S.L. 2007.

SARLET, Ingo Wolfgang. A eficácia dos direitos fundamentais. 7. ed. rev., atual. e ampl. Porto Alegre: Livraria do Advogado, 2007a.

SARLET, Ingo Wolfgang. Mínimo existencial e direito privado: apontamentos sobre algumas dimensões da possível eficácia dos direitos fundamentais sociais das relações jurídico-privadas. In: DE SOUZA NETO, Cláudio Pereira; 
SARMENTO, Daniel. A constitucionalização do direito: fundamentos teóricos e aplicações específicas. Rio de Janeiro: Lumen Juris, 2007b. p. 336-337.

SHIVA, Vandana. Guerras por água: privatização, poluição e lucro. Tradução de Georges Kormikiaris. São Paulo: Radical Livros, 2006.

SMETS, Henri. Le droit à l'eau. Disponível em: <www.worldwater.council. org>. Acesso em: 8 jul. 2011.

TAVARES, Elaine. Água potável - direito fundamental do ser humano. Disponível em: <www.recantodasletras.com.br/discursos/791994>. Acesso em: 25 jul. 2011.

TELLES, Dirceu D'Alkmin; COSTA, Regina Pacca (Coord.). Reúso da água: conceitos, teorias e práticas. 2. ed. São Paulo: Blucher; FAT, 2010.

TORRES, Ricardo Lobo. O direito ao mínimo existencial. Rio de Janeiro: Renovar, 2009.

VIANA, Thiago Henrique Fedri. Manual dos direitos difusos e coletivos. Campinas, SP: Millennium, 2010. 